\title{
Static Bending Performances of Cross-Laminated Wood Panels Made with Tropical and Temperate Woods ${ }^{1}$
}

\author{
Jin-Woong Byeon ${ }^{2} \cdot$ Tae-Ho Kim² $•$ Jae-Kyung Yang $^{2} \cdot$ Hee-Seop Byeon ${ }^{2} \cdot$ Han-Min Park $\mathbb{D}^{2, \dagger}$
}

\begin{abstract}
In this study, for using effectively domestic (temperate) small and medium diameter logs as a wooden floorboard, cross-laminated wood panels were manufactured using domestic larch and tulip woods as a base material for teak and merbau wood flooring, and static bending strength performances were measured to investigate the applicability as the base materials of wooden flooring in place of plywood. Static bending MOE was much influenced by the strength performances of the top layer lamina than that of the laminae for base materials. Bending MOR showed the higher values in tulip wood that was hardwoods than in larch wood that was softwoods regardless of the strength performances of the top layer laminae, and it was found that the values were much influenced by the strength performances of the base materials used in the core and bottom layers. However these values were $1.4-2.5$ times higher values than the bending strength of the wooden floorboards specified in KS, it was found that it can be sufficiently applied to the base materials of wooden floorboards in place of plywood.
\end{abstract}

Keywords: cross-laminated wood panels, base material, wood flooring, bending modulus of elasticity, bending modulus of rupture

\section{INTRODUCTION}

With the strengthening of resource protection policies around the world, it is becoming increasingly difficult to secure high quality timber, and it is demanded to expand the use of domestic small and medium diameter logs, which are increasingly accumulating due to the success of long-term forest conservation and afforestation.

There are two main types of laminated wood. One of them is a conventional glulam which is laminated in parallel with the grain direction of lamina, and the other is cross-laminated timber in which the grain direction is orthogonally laminated. They are actively used as a building material. The CLT has excellent properties such as dimensional stability and large area applicability, however, the strength performance generally tends to be somewhat lower than that of the glulam. Because the laminae perpendicular to the grain are arranged in the core layer and the shape is easily affected by the shear force due to the difference in the strength performance of the faces layer and the core layer. In general, the use of glulam and CLT is

${ }^{1}$ Date Received August 30, 2018, Date Accepted November 12, 2018

2 Division of Environmental Forest Science, Institute of Agriculture \& Life Science, Gyeongsang National University, Jinju 52828, Republic of Korea

† Corresponding author: Han-Min Park (e-mail: phm0691@gnu.ac.kr, ORCID: 0000-0001-6322-5985) 
not active in Korea due to the status of forest timber. Recently, in Japan, J-panel has been developed as a substitute for plywood, it is the same structure as CLT but has 20 to $30 \mathrm{~mm}$ thick. These small cross-laminated woods are wood-based materials that can efficiently use small and medium diameter logs rather than large diameter logs, and it is considered to be superior to CLT in that it can be applied to forests in Korea. However, since the factory system is not established compared to the plywood, it has a disadvantage in terms of cost, so it is necessary to switch to a product with high added value. The studies on CLT have been remarkably carried out with respect to mechanical performances (Gülzow et al., 2011; Stelger et al., 2012; Okabe et al., 2014; Goto et al., 2014; Nakashima et al., 2014; Ido et al., 2014; Sebera et al., 2015; Song and Hong, 2016) and the connection parts(Gavric et al., 2015a, 2015b; Pang et al., 2017). In recent years, for the purpose of searching for efficient utilization, using widely and improving performance, CLT using Korean domestic woods (Oh et al., 2015; Park et al., 2016; Byeon et al., 2017) and core-plywood CLT arranging plywood in the core (Choi et al., 2015) have been developed and evaluated for various performances.

In the previous studies, we manufactured various cross-laminated woods made with Japanese cedar(Park et al., 2001; 2006; 2014), with three softwoods and three hardwoods (Park et al., 2016; Byeon et al., 2017), and with five species(Park et al., 2003; 2009) mixing two softwoods and three hardwoods and investigated the effects of annual ring angles, shear moduli, and thickness of constitution laminae on static bending strength performances. As a result, it was found that the mechanical properties were remarkably affected by annual ring angles, wood species, shear moduli, and thicknesses of perpendicular-direction laminae positioned in the core as well as the face of panels.

The floorboards distributed on the market are divided into three types which are the wood floorboard covering sawn woods of 3 - $4 \mathrm{~mm}$ thick on plywood base, the ondol floorboard covering sliced veneers on plywood base, and the hardboard floorboard made with hardboard more than $0.8 \mathrm{Mg} / \mathrm{m}^{3}$ in density. Most of the plywood is used as the base materials for the wooden floorboards.

In this study, in order to use the cross-laminated wood panels as the base material for floorboards in place of plywood used mainly as base materials of wooden or ondol floorboards, cross-laminated wood panels were manufactured by using tropical woods as the top layer materials and domestic softwoods and hardwoods as a base materials, and the basic mechanical properties of cross-laminated wood panels were investigated.

\section{MATERIALS and METHODS}

\subsection{Specimen preparation}

Two domestic woods and Two tropical woods in south pacific were selected for this study. They were Japanese larch(Larix kaempferi), tulip tree(Liriodendron tulipifera L.), merbau(Intsia bijuga) and teak(Tectona grandis). The elements of $80 \mathrm{~mm}(\mathrm{~W}) \times 7 \mathrm{~mm}(\mathrm{H}) \times$ $720 \mathrm{~mm}(\mathrm{~L})$ size were made from the sawn woods of four wood species, and were used as longitudinaldirection laminae. The nine sawn woods of Japanese larch and tulip tree of $80 \mathrm{~mm}(\mathrm{~W}) \times 7 \mathrm{~mm}(\mathrm{H}) \times 720 \mathrm{~mm}(\mathrm{~L})$ were widthwise-jointed and the square widthwise-jointed plates were manufactured. And they were cut to the $80 \mathrm{~mm}$ width and were used as perpendicular-direction laminae.

Cross-laminated wood panels were consisted of teak and merbau longitudinal-direction laminae in the top layers, Japanese larch and tulip tree perpendiculardirection laminae in the core layers and Japanese larch and tulip tree longitudinal-direction laminae in the bottom layers. And the densities of each laminae were measured, and were cured with aqueous polymeric 
isocyanate resin (MPU-500, Okong Co., Ltd. 15 parts of curing agent was added to 100 parts of the adhesive base). The adhesive was spreaded on both side with the amount of $300 \mathrm{~g} / \mathrm{m}^{2}$, and the compression force of $0.34 \mathrm{MPa}$ was applied using a torque wrench, and the compression was performed for 24 hours. After the compression, the specimens were maintained for more than 2 weeks in a constant temperature and humidity room of $20^{\circ} \mathrm{C}, 65 \% \mathrm{RH}$, and the excess adhesive was removed and cut into $20 \mathrm{~mm}(\mathrm{~W}) \times 21 \mathrm{~mm}(\mathrm{H}) \times 350 \mathrm{~mm}$ (L) size as shown in Fig. 1. These were used as the specimens. The symbols used for the test specimens were teak (T), merbau (M), Japanese larch (La), and tulip tree (Tu). Therefore each laminated wood panels were named as follows; teak-larch cross- laminated wood panels (TLa), teak-tulip tree cross- laminated wood panels (TTu), merbau-larch cross- laminated wood panels (MLa), and merbau-tulip cross- laminated wood panels (MTu). As described above, four types of the cross-laminated wood panels were subjected to static bending test for total of 16 test specimens so that each type could be tested four times.

\section{Species : Tropical woods : Teak, Merbau, \\ Domestic woods: Japanese larch, Tulip tree.}

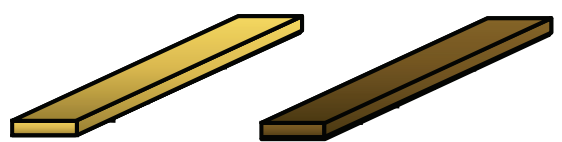

Teak (T)

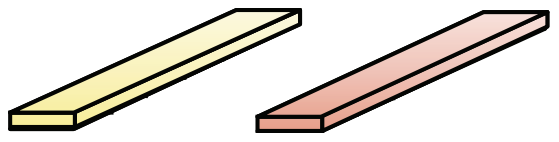

Tulip tree (Tu) Japanese larch (La)

Longitudinal-direction lamina

$(20 \times 7.0 \times 360 \mathrm{~mm})$

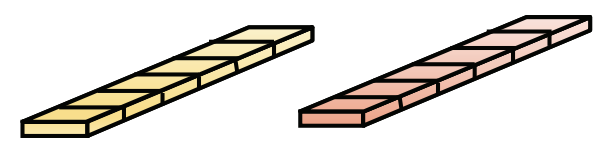

Tulip tree (Tu) Japanese larch (La)

Perpendicular-direction lamina

$(20 \times 7.0 \times 360 \mathrm{~mm})$

Three-ply glued lamination

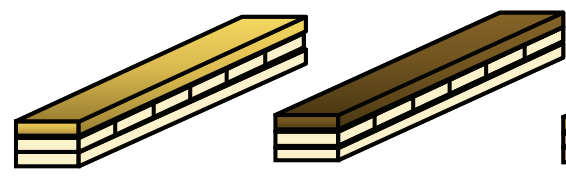

TTu type
MTu type

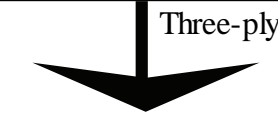

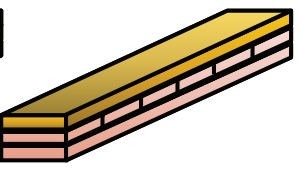

TLa type

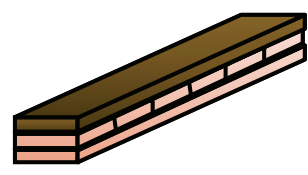

MLa type

Cross-laminated wood specimens (20× $21 \times 350 \mathrm{~mm})$

Fig. 1. Schematic diagram of cross-laminated wood specimens made with tropical and domestic woods. TTu: Teak-Tulip, MTu: Merbau-Tulip, TLa: Teak-Larch, MLa: Merbau-Larch. 


\subsection{Bending strength properties test}

Static bending test for cross-laminated wood specimens was conducted by four-point loading using universal test machine (Instron 6569). The span was $300 \mathrm{~mm}$, the distance from a loading point to a supporting point was $100 \mathrm{~mm}$, and the cross-head rate was set at 5.0 $\mathrm{mm} / \mathrm{min}$. Static bending modulus of elasticity (MOE) was calculated using Eq. (1), and bending modulus of rupture (MOR) was calculated using Eq. (2).

$$
E=P a\left(3 l^{2}-4 a^{2}\right) / 4 b h^{3} y
$$

where, $P$ : Load, $a$ : Distance between loading point and supporting point, $l:$ Span, $b$ : Width of specimen, $h$ : Thickness of specimens, $y$ : Deflection.

$$
\sigma=3 P_{\max } a / b h^{2}
$$

where, $P_{\max }$ : Maximum load, $a$ : Distance between loading point and supporting point, $b$ : Width of specimen, $h$ : Thickness of specimens.

\section{RESULTS and DISCUSSION}

\subsection{Bending MOE of cross-laminated wood panels}

The results of static bending test of cross-laminated wood panels made with tropical and domestic woods are shown in Table 1, and static bending MOE and specific MOE expressed as the ratio to density are shown in Fig. 2.

Static bending MOE showed the highest value of 13.1 GPa in MTu type with merbau laminated on the domestic tulip tree, and the lowest value of $10.6 \mathrm{GPa}$ in TLa type with teak laminated on the domestic larch. The values were in the order of $\mathrm{MTu}>\mathrm{MLa}>\mathrm{TTu}$ $>$ TLa. These values showed a low values $0.70-0.72$ times of teak and $0.57-0.59$ times of merbau. It was found that the extent of the decrease was markedly lower in the cross-laminated wood panels made with

Table 1. Results of static bending test of cross-laminated wood panels made with tropical and domestic woods

\begin{tabular}{ccccccccc}
\hline Type & & $\begin{array}{c}\rho \\
\left(\mathrm{Mg} / \mathrm{m}^{3}\right)\end{array}$ & $\begin{array}{c}\mathrm{E} \\
(\mathrm{GPa})\end{array}$ & $\begin{array}{c}\mathrm{SE} \\
(\mathrm{GPa})\end{array}$ & $\begin{array}{c}\sigma_{\text {PLST }} \\
(\mathrm{MPa})\end{array}$ & $\begin{array}{c}\sigma \\
(\mathrm{MPa})\end{array}$ & $\begin{array}{c}\mathrm{S} \sigma \\
(\mathrm{MPa})\end{array}$ & $\begin{array}{c}\varepsilon \\
\left(10^{-2} \mathrm{~mm} / \mathrm{mm}\right)\end{array}$ \\
\hline \hline \multirow{2}{*}{$\mathrm{T}$} & & 0.724 & 15.1 & 20.9 & 70.0 & 118 & 163 & 1.21 \\
& $\mathrm{CV}(\%)$ & 2.8 & 3.9 & 5.8 & 5.8 & 3.0 & 4.5 & 6.6 \\
\hline $\mathrm{M}$ & & 0.789 & 22.3 & 28.3 & 90.3 & 143 & 181 & 1.09 \\
& $\mathrm{CV}(\%)$ & 2.1 & 3.6 & 4.3 & 3.9 & 4.1 & 4.9 & 6.2 \\
\hline \multirow{2}{*}{$\mathrm{TTu}$} & & 0.573 & 10.9 & 19.1 & 52.5 & 90.0 & 157 & 1.33 \\
& $\mathrm{CV}(\%)$ & 1.5 & 6.1 & 7.2 & 5.5 & 1.7 & 2.9 & 13.3 \\
\hline \multirow{2}{*}{$\mathrm{TLa}$} & & 0.582 & 10.6 & 18.1 & 39.0 & 56.2 & 97.0 & 0.87 \\
& $\mathrm{CV}(\%)$ & 3.4 & 6.8 & 4.0 & 8.0 & 23.0 & 24.4 & 25.3 \\
\hline \multirow{2}{*}{$\mathrm{MTu}$} & & 0.634 & 13.1 & 20.6 & 56.8 & 98.9 & 156 & 1.05 \\
& $\mathrm{CV}(\%)$ & 1.7 & 1.2 & 2.7 & 13.5 & 7.7 & 7.7 & 8.8 \\
\hline \multirow{2}{*}{$\mathrm{MLa}$} & & 0.643 & 12.8 & 19.9 & 36.5 & 54.4 & 84.6 & 0.58 \\
& $\mathrm{CV}(\%)$ & 1.9 & 6.7 & 7.1 & 8.2 & 7.3 & 7.9 & 20.3 \\
\hline
\end{tabular}

Notes; $\rho$ : Density, E: Modulus of elasticity (MOE), $\sigma_{\mathrm{PLST}}$ : Proportional limit stress, $\sigma$ : Modulus of rupture (MOR), SE: Specific modulus of elasticity (= MOE/specific gravity), S $\sigma$ : Specific modulus of rupture (= MOR/specific gravity), $\varepsilon$ : Strain at maximum load. CV: Coefficient of variation, T: Teak, M: Merbau, TTu: Teak-Tulip. TLa: Teak-Larch, MTu: Merbau-Tulip. MLa: Merbau-Larch. 

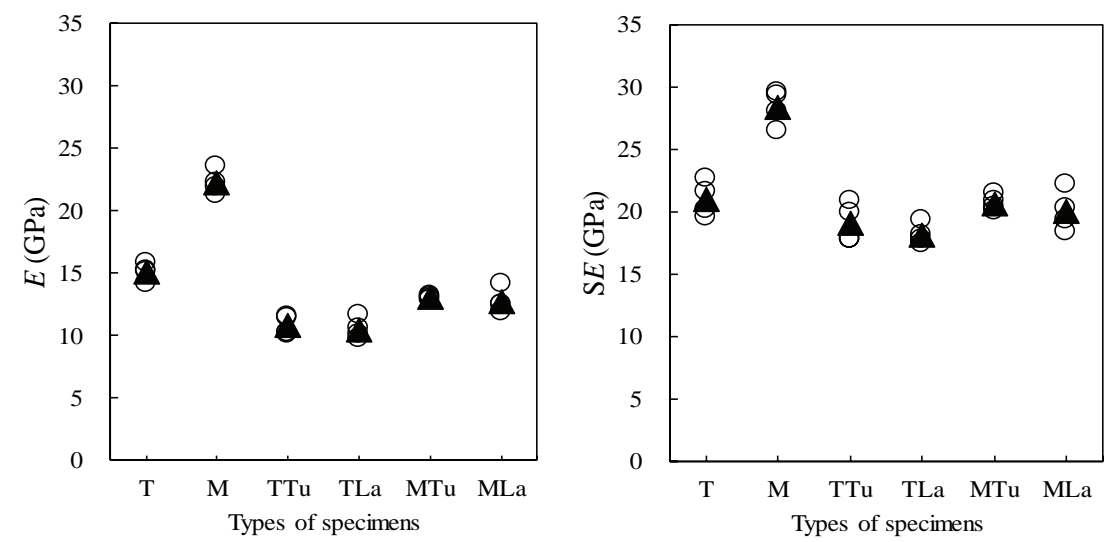

Fig. 2. Bending $\mathrm{MOE}(E)$ and specific MOE $(S E)$ of cross-laminated wood specimens made with tropical and domestic woods.

Note: T: Teak, M: Merbau, TTu: Teak-Tulip, TLa: Teak-Larch, MTu: Merbau-Tulip, MLa: Merbau-Larch. Legend: $\boldsymbol{\Delta}$ : Average MOE.

merbau than in that made with teak. These values showed 1.1 - 1.3 times higher values than those of tulip three-ply cross-laminated wood panels and 1.0 1.2 times higher values than those of Japanese larch three-ply cross-laminated wood panels in the previous report (Park et al., 2016). TLa type with high MOE of teak had lower values than those of larch three-ply cross-laminated wood panels. It was considered because the deviation between the tested specimens due to defects such as knots, slope of grain and nonstraight grain was great. In the previous report, the specimens that had defect-free and straight longitudinal-radial direction grains were used, however in this study a large cross-laminated wood panels of an actual floorboard size were manufactured, and used as specimens after cutting as small size. Therefore, the possibility of large deviation between the tested specimens was high.

Specific bending MOE showed the highest value of 20.6 GPa in MTu type with merbau laminated on the tulip tree base, and showed the lowest of 18.1 GPa in TLa type with teak laminated on the larch base. These values were 1.6 - 1.8 times higher than static bending MOE, and it was found that the extent of the increase was markedly great at the specimen types mixed-laminating teak with low density.

\subsection{Proportional limit stress of cross-laminated wood panels}

Proportional limit stresses of cross-laminated wood panels made with tropical and domestic woods are shown in Fig. 3.

Proportional limit stresses showed the highest value of 56.9 MPa in MTu type with merbau laminated on tulip tree base, and the lowest value of $36.5 \mathrm{MPa}$ in TLa type with teak laminated on larch base. The values were in the order of MTu $>$ TTu $>$ TLa $>$ MLa. These values showed a low values of $0.56-0.75$ times of teak and $0.40-0.63$ times of merbau. It was found that the extent of the decrease was markedly lower in the cross-laminated wood panels made with merbau than in that made with teak. These values showed 1.1 - 1.2 times higher values than those of tulip three-ply cross-laminated wood panels, however it was 0.69 - 0.74 times lower values than those of Japanese 


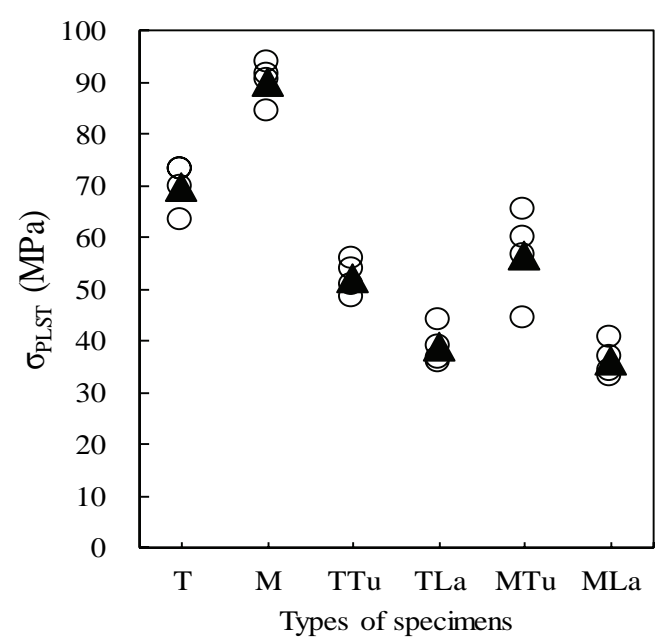

Fig. 3. Proportional limit stress of cross-laminated wood panels made with tropical and domestic woods.

Note: T, M, TTu, TLa, MTu and MLa: See the note in Fig. 2. Legend: $\boldsymbol{\Delta}$ : Average MOE.

larch three-ply cross-laminated wood panels in the previous report (Park et al., 2016). This is considered to be caused by an increase in the deformation of the core layer due to the shear force in addition to the defects of

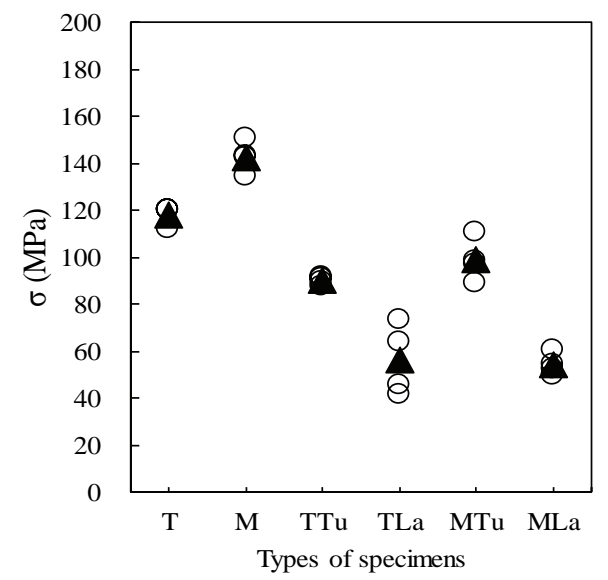

the large tested specimens as mentioned in the bending MOE. The higher the strength of the top layer, the greater the difference in the strength performance between the face and the core layers of the crosslaminated wood panel, and the deflection caused by shear force which is influenced by the ratio of bending MOE to shear modulus $(E / G)$ increases, and the deformation of core layer due to shear becomes large, and the proportional limit stress becomes low.

\subsection{Bending modulus of rupture of cross-laminated wood panels}

Bending MOR and specific MOR of cross-laminated wood panels made with tropical and domestic woods are shown in Fig. 4.

Bending MOR showed the highest value of 98.9 $\mathrm{MPa}$ in MTu type with merbau laminated on tulip tree base, and the lowest value of 10.6 GPa in TLa type with teak laminated on larch base. The values were in the order of MTu $>\mathrm{TTu}>\mathrm{TLa}>\mathrm{MLa}$, and were slightly different from bending MOE. This can

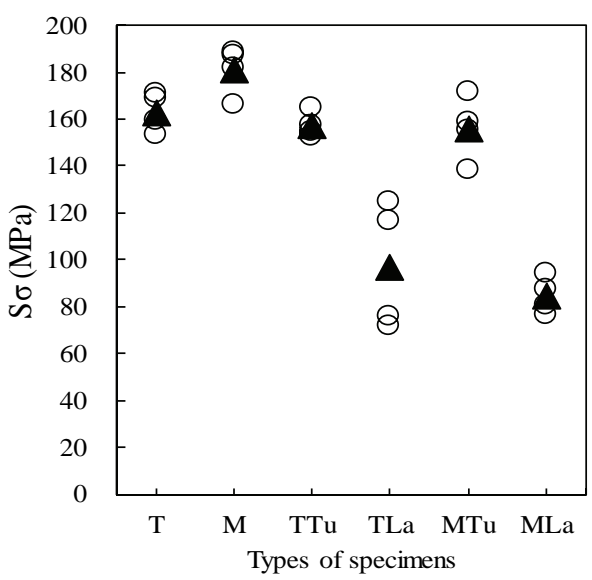

Fig. 4. Bending MOR and specific MOR (SMOR) of cross-laminated wood panels made with tropical and domestic woods.

Note: T, M, TTu, TLa, MTu and MLa: See the note in Fig. 2.

Legend: $\boldsymbol{\Delta}$ : Average MOE. 


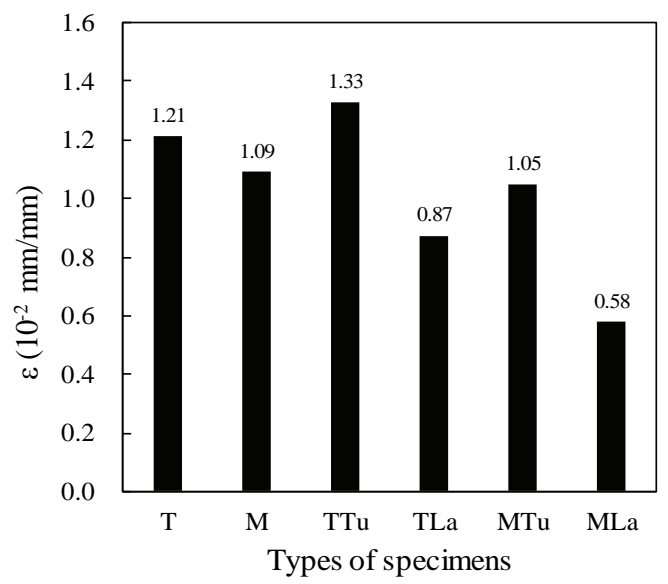

Fig. 5. Strain $(\varepsilon)$ at the maximum load of the crosslaminated wood panels made with tropical and domestic woods.

be explained by the strain of cross-laminated wood panels shown in Fig. 5. In general, the bending MOR are proportional to strain, and the bending MOR tends to increase as the strain increases. Therefore, TTu type laminated by teak with the large strain showed a remarkably great strain compared with a low MOE, and this is considered to have an effect on increasing the bending MOR. These values showed a low values of $0.48-0.76$ times of teak, and $0.38-0.69$ times of merbau. It was found that the extent of the decrease was markedly lower in the cross-laminated wood panels made with merbau than in that made with teak, and was greater in larch base than in tulip tree base. These values showed 1.3 - 1.5 times higher values than those of tulip three-ply cross-laminated wood panels and $0.74-0.77$ times lower values than those of Japanese larch three-ply cross-laminated wood panels in the previous report (Park et al., 2016). The reason that the values were low compared with that of Japanese larch three-ply cross-laminated wood panels is considered because of the various defects of large size specimens and shear failure of the core layer not the bottom layer with increase of shear deformation as mentioned above. These values showed 1.4 - 2.5 times of the bending strength (40 $\mathrm{MPa}$ ) specified in Korean industrial standard (KS) for the floorboards (KS, 2016, 2017), and it was considered that domestic small and medium diameter logs could be used as a base material for floorboards in place of plywood.

Specific MOR showed the highest value of $157 \mathrm{MPa}$ in TTu type with teak laminated on tulip tree base and showed the lowest value of 84.6 MPa in MLa type with merbau laminated on larch base. MTu type with merbau laminated on larch base showed 156MPa and there was little difference from TTu type. These values were 1.6 - 1.7 times higher than bending MOR, and it was found that the extent of the increase was markedly great at the specimen types mixed-laminating teak with low density compared with merbau with high density.

\section{CONCLUSION}

In this study, for using domestic small and medium diameter logs as a base material of wood flooring, cross-laminated wood panels were manufactured by using teak and merbau woods for top layer materials and domestic larch and tulip woods for core and bottom layer materials, and we investigated static bending strength performances of cross-laminated wood panels. As a results, static bending MOE of cross- laminated wood panels mixed-laminating tropical woods and domestic woods showed the highest values in the panel types with merbau laminated at the top layer regardless of base materials. It was found that the value showed $0.70-0.72$ times of teak and $0.57-0.59$ times of merbau, and the extent of the decrease was greater in merbau with a high density. Also, bending proportional limit stress and bending MOR were highest in the panel type with merbau laminated on tulip base, and the lowest in the panel type with merbau laminated on larch base. For the MOR, this value showed 0.48 - 0.76 times lower 
values compare with teak and 0.38 - 0.69 times lower value compare with merbau. However, these values showed 1.4-2.5 times higher values than the values of the wooden floorboards specified in KS, it was found that this was able to be used as a base material for wood flooring in place of plywood.

\section{REFERENCES}

Byeon, J.W., Kim, T.H., Yang, J.K., Byeon, H.S., Park, H.M. 2017. Bending creep property of crosslaminated woods made with six domestic species. Journal of the Korean Wood Science and Technology 45(6): 689-702.

Choi, C., Yuk, C.R., Yoo, J.C., Park, J.Y., Lee, C.G., Kang, S.G. 2015. Physical and mechanical properties of cross laminated timber using plywood as core layer. Journal of the Korean Wood Science and Technology 43(1): 86-95.

Gülzow, A., Richter, K., Stelger, R. 2011. Influence of wood moisture content on bending and shear stiffness of cross-laminated timber panels. European Journal of Wood and Wood Products 69: 193-197. Goto, T., Fukushima, A., Nakayama, S., Furono, T. 2014. Bending properties of missed-species, three-ply CLTs (Cross-Laminated Timbers) with inner layer of sugi. Mokuzai Gakkaishi 60: 336-345. In Japanese with summary in English.

Gavric, I., Fragiacomo, M., Ceccotti, A. 2015a. Cyclic behavior of typical metal connectors for crosslaminated (CLT) structures. Materials and Structures 48: 1841-1857.

Gavric, I., Fragiacomo, M., Ceccotti, A. 2015b. Cyclic behavior of typical screwed connections for cross-laminated (CLT) structures. European Journal of Wood and Wood Products 73: 179-191.

Ido, H., Nagao, H., Miura, S., Miyatake, A. 2014. Compressive strength properties perpendicular to the grain of cross-laminated timber (CLT) composed of sugi laminations. Mokuzai Gakkaishi 60: 16-22. In Japanese with summary in English.

Korean Industrial Standards (KS F 3111). 2016. Natural wood veneer flooring board.

Korean Industrial Standards (KS F 3126). 2017. Decorative wood-based flooring board.

Nakashima, S., Kitamori, A., Komatsu, K. 2014. Embedment and shear strengths of cross laminated timber and their dependence on angular orientation. Mokuzai Gakkaishi 60: 216-226. In Japanese with summary in English.

Oh, J.K., Lee, J.J., Hong, J.P. 2015. Prediction of compressive strength of cross-laminated timber panel. Journal of Wood Science 61: 28-34.

Okabe, M., Yasumura, M., Kobayashi, K., Fujita, K. 2014. Prediction of bending stiffness and moment carrying capacity of sugi cross-laminated timber. Journal of Wood Science 60: 49-58.

Pang, S.J., Kim, K.M., Park, S.H., Lee, S.J. 2017. Bending behavior of nailed-jointed cross-laminated timber loaded perpendicular to plane. Journal of the Korean Wood Science and Technology 45(6): 728-736.

Park, H.M., Fushitani, M. 2014. Calculations of shear moduli of three-ply cross-laminated wood panels from shear moduli of individual laminae. Wood Fiber Science 46: 195-205.

Park, H.M., Fushitani, M., Byeon, H.S. 2009. Derivation of an equation for calculating shear modulus of three-ply laminated material beam from shear moduli of individual laminae and its application. Journal of Wood Science 55: 181-189.

Park, H.M., Fushitani, M., Byeon, H.S., Yang, J.K. 2016. Static bending strength performances of cross-laminated wood panels made with six species. Wood Fiber Science 48: 68-80.

Park, H.M., Fushitani, M., Ohtsuka, T., Nakajima, T., Sato, K., Byeon, H.S. 2001. Effect of annual ring angle on static bending strength performances of 
cross-laminated woods made with sugi wood. Mokuzai Gakkaishi 47: 22-32. In Japanese with summary in English.

Park, H.M., Fushitani, M., Sato, K., Kubo, T., Byeon, H.S. 2003. Static bending strength performances of cross-laminated woods made with five species. Journal of Wood Science 49: 411-417.

Park, H.M., Fushitani, M., Sato, K., Kubo, T., Byeon, H.S. 2006. Bending creep performances of three-ply cross-laminated woods made with five species. Journal of Wood Science 52: 220-229.

Sebera, V., Muszyński, L., Tippner, J., Noyel, M., Pisaneschi, T., sundberg B. 2015. FE analysis panel subjected to torsion and verified by DIC. Materials and Structures 48: 451-459.

Song, Y.J., Hong, S.I. 2016. Evaluation of bonding strength of larch cross-laminated timber. Journal of the Korean Wood Science and Technology 44(4): 607-615.

Stelger, R., Gülzow, A., Czaderski, C., Howald, M., Niemz, P. 2012. Comparison of bending stiffness of cross-laminated solid timber derived by modal analysis of full panels and by bending tests of strip-shaped specimens. European Journal of Wood and Wood Products 70: 141-153. 